\title{
Industrial Applications of Si-based Ceramics
}

\author{
Jens Eichler ${ }^{\dagger}$ \\ ESK Ceramics GmbH \& Co. KG, D-87437 Kempten, Germany \\ (Received May 25, 2012; Revised July 12, 2012; Accepted July 13, 2012)
}

\begin{abstract}
Due to their unique combination of properties, Si-based ceramics, such as silicon carbide ( $\mathrm{SiC})$, silicon nitride $\left(\mathrm{Si}_{3} \mathrm{~N}_{4}\right)$ and silicon oxide $\left(\mathrm{SiO}_{2}\right.$ as fused silica), have a range of industrial applications in fields such as the chemical industry, aluminum manufacturing, oil and gas production and solar cell production. For each materials group, examples of typical applications from various industry sectors are presented while taking into account the property fingerprint.
\end{abstract}

\section{Key words : Industrial application, Silicon nitride, Silicon carbide}

\section{Introduction}

E SK Ceramics, a subsidiary of Ceradyne Inc., develops and manufactures pioneering products in the fields of advanced ceramics, ceramic powders and frictional coatings. For many years, ESK has been known as a quality supplier of non-oxide ceramics. Fig. 1(a) shows an overview of ESK's materials portfolio. In recent years ESK has developed new materials and, together with our customers, deployed nonoxide ceramics in a range of new applications. We continually develop innovative product solutions and use a wide range of process technologies.

For new applications, non-oxide ceramics are selected based on the combination of properties that suits the specific application. This is the characteristic property fingerprint (Fig. 1(b)) for each individual applications field. This paper gives an overview of typical applications for siliconbased ceramics and tries to emphasize the unique combination of properties that makes ceramics the perfect solution. This may help as a guideline for future solutions to specific technical problems.

\section{Silicon Carbide-Properties and Applications}

Silicon carbide (ESK brand name: EKasic ${ }^{\circledR}$ ) is used in a wide range of markets and produced in different qualities. The key to its performance is its microstructure. Fig. 2 shows typical microstructures of a solid-state sintered fine $\left(\right.$ EKasic $^{\circledR} \mathrm{F}$ ) and a coarse grained (EKasic ${ }^{\circledR} \mathrm{C}$, see below) material as well as two tribologically optimized microstructures having graphite inclusions $\left(\right.$ EKasic $^{\circledR} \mathrm{G}$ ) or pores (EKa$\left.\operatorname{sic}^{\circledR} \mathrm{P}\right)$. To complete the portfolio a liquid-phase sintered

${ }^{\dagger}$ Corresponding author : Jens Eichler

E-mail : JEichler@esk.com

Tel : +49-831-5618-508 Fax : +49-831-5618-8508
(EKasic ${ }^{\circledR} \mathrm{T}$ plus) quality is included showing typical properties and advantages in the application. From here on, the focus will be on solid-state sintered silicon carbide.

\subsection{Seals and bearings for industrial pumps \\ Property fingerprint:}

- Solid-state sintered $\mathrm{SiC}$ (SSiC) became the standard for chemical pump bearings and seals due to its very good chemical resistance to bases as well as acids.

- The corrosion resistance of SSiC can even be enhanced by using coarse grained EKasic ${ }^{\circledR} \mathrm{C}$, due to the interlocking of grains.

- Tribological performance is another important property of SSiC for the application. Optimized microstructures, such as those of EKasic ${ }^{\circledR} \mathrm{G}$ and P, offer reliability and optimize performance.

In a benchmark study, ${ }^{1)}$ EKasic $^{\circledR}$ F, C, P and G were tested in a pump test rig as process-fluid-lubricated seal rings simulating standard pump conditions, as well as mixed lubrication conditions. The test rig has already been described elsewhere. ${ }^{2)}$ Three other typical pump sealing materials were included in the benchmark study:

- Material 1: Fine-grained SiC structure with 45 vol-\% graphite

- Material 2: SSiC material with 4-5 vol-\% pores, fine microstructure

- Material 3: Siliconized carbon with 43 vol.-\% graphite and a free silicon content of 4 vol.- $\%$.

In a first test, the fluid pressure was increased steadily up to a maximum of 125 bar until failure of one of the two seal pair rings. The typical pressure range for this seal design is 25-40 bar. Two materials (EKasic ${ }^{\mathbb{B}}$ P \& G) passed the 125 bar criterion and were further tested at 100 bar until failure. Fig. 3 shows the results of the benchmark study concerning robustness. EKasic ${ }^{\circledR} \mathrm{G}$ was the best material in this test. 


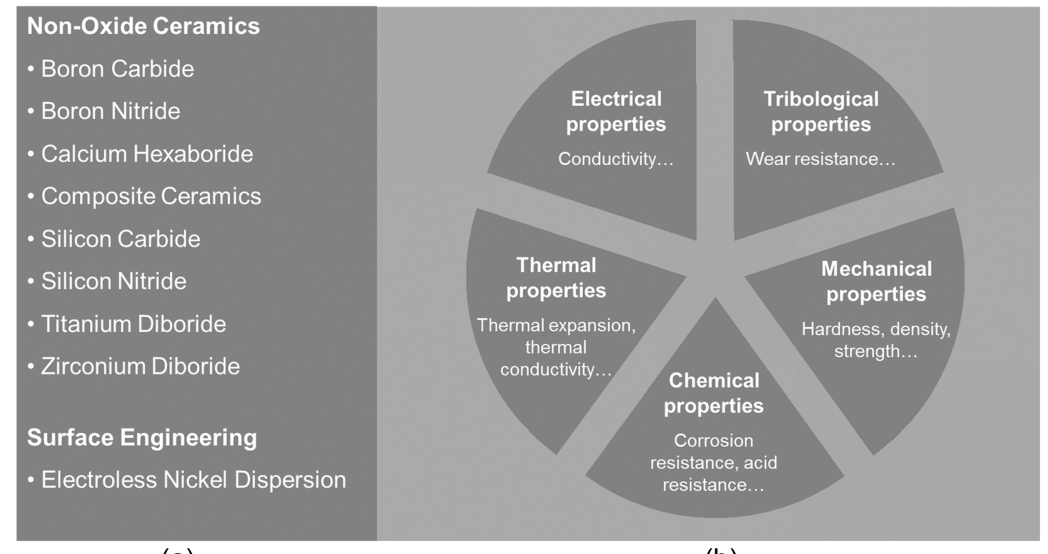

(a)

(b)

Fig. 1. ESK product portfolio and typical property spectrum.

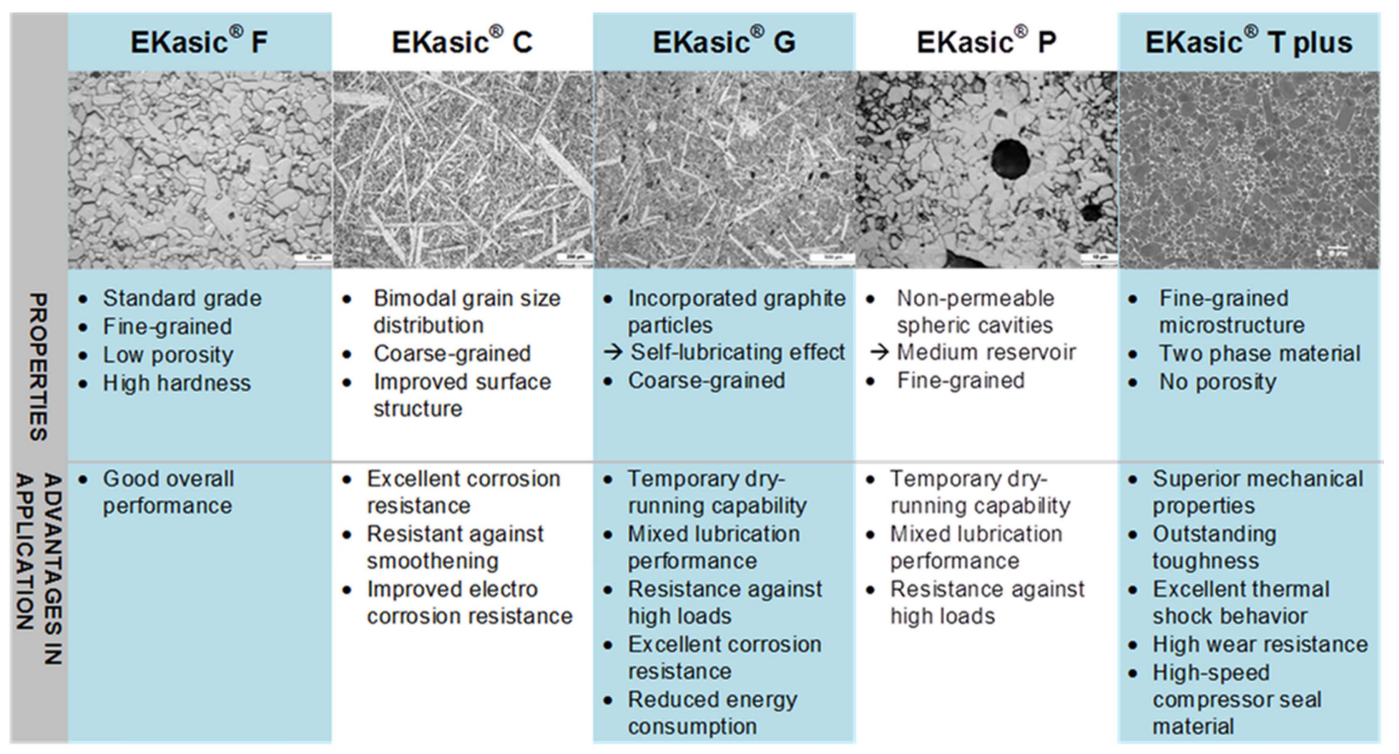

Fig. 2. EKasic ${ }^{\circledR}$ materials overview showing the influence of microstructure on properties and the respective advantages for the application.

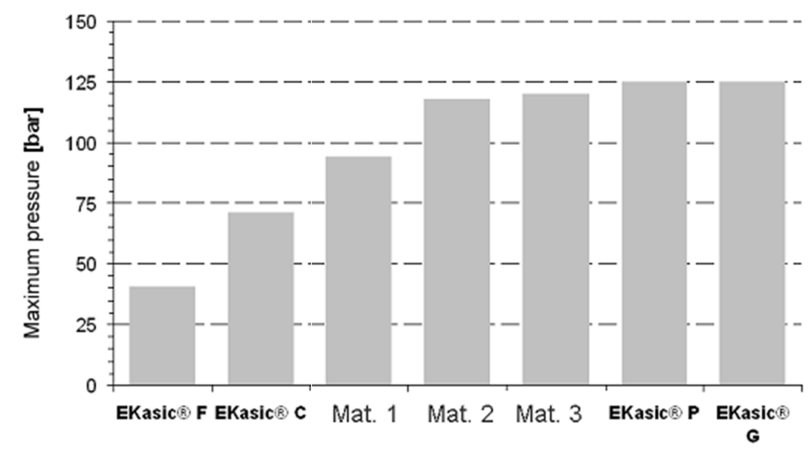

Fig. 3. Benchmark for robustness of typical chemical pump seal ring materials.

By comparing power consumption in the 25-40 bar range, a benchmark ranking was made based on the energy uptake by the seal pairing. This is the typical pressure range for the application for the design of this seal geometry. EKasic ${ }^{\circledR} G$ and Material 1 were the best two materials in this test.

In terms of overall performance EKasic ${ }^{\circledR} \mathrm{G}$, was the best material in the benchmark study, underlining the feedback by the pump industry.

\subsection{Oil and gas production (PetroCeram ${ }^{\circledR}$ Ceramic Sand Screens)}

Property fingerprint

- Chemical resistance and erosion resistance are the two main material properties necessary for this application.

Oil and gas will continue to play an important role for the world energy mix even after "peak oil." In order to economically optimize existing oil and gas resources, new and existing wells need "enhanced oil recovery" techniques for high yield and economic oil and gas production. The challenge in some geological formations is high sand extraction, leading to premature failure due to erosion of the metal filters currently used. The filter has to keep the sand out of the pro- 


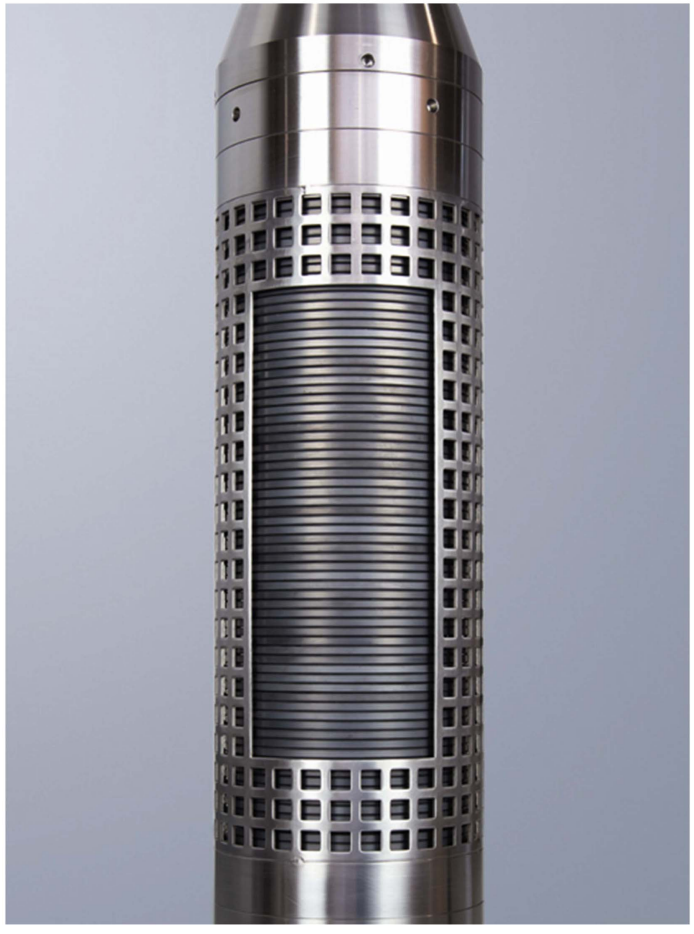

Fig. 4. PetroCeram ${ }^{\circledR}$ sand screen.

duction pipe while enabling high flow rates for oil and gas. Often corrosive media are used to clear blocked filters, as well as for some enhanced oil recovery techniques, ${ }^{3)}$ which adds another stress factor for screens.

EKasic $^{\circledR}$ offers a good combination of chemical resistance, erosion resistance and mechanical stability. By incorporating an intelligent ring design into the system, PetroCeram ${ }^{\circledR}$ (Fig. 4) has provided the industry a superior sand control technology. Longer lifetime, corrosion stability, low pressure drop and higher temperature capability are the results of technical ceramic solutions for the oil and gas industry. The synergistic combination of outstanding ceramic material characteristics and specific engineered designs allows maximized productivity and efficiency. PetroCeram ${ }^{\circledR}$ systems offer increased lifetime, less maintenance and fewer workovers.

\subsection{Flow reactors and heat exchangers made from}

\section{silicon carbide}

Property fingerprint:

- Chemical stability, abrasion resistance and high thermal conductivity are the combination of properties needed for a new class of heat exchangers and flow reactors for challenging conditions.

The combination of thermal conductivity $(>110 \mathrm{~W} / \mathrm{mK}$ at room temperature), good strength (especially compared to glass and polymers) and very good chemical resistance make solid-state sintered silicon carbide the ideal material for producing gas-tight flow reactors and heat exchangers for challenging chemical reactions and processes (e.g. exothermic, corrosive, ....). If abrasive particles have to be pro-

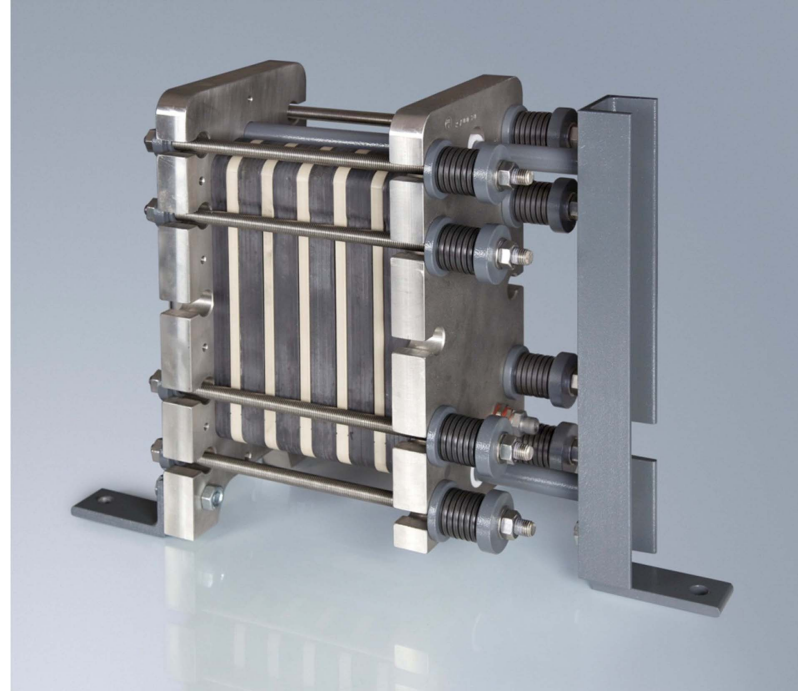

Fig. 5. Flow reactor system with frame and connections.

cessed, the high abrasion resistance of silicon carbide, due to its excellent hardness, is a perfect add-on.

Specially designed silicon carbide plates are joined by an ESK proprietary process to form monolithic apparatus that can be combined with a frame and connections to form a flow reactor or heat exchanger. The important step in this case was to fulfill the customer's need for a plug-in system for performing the necessary reactions or processes (Fig. 5).

\subsection{Fillers for polymers}

Property fingerprint

- Adding SiC as a filler to a polymer matrix enhances the abrasion resistance due to the high hardness of silicon carbide.

- Increasing thermal conductivity is another important task for fillers (e.g. hexagonal boron nitride - BORONID ${ }^{\circledR}$ TC)

- The electrical conductivity of the polymer matrix can be increased by adding titanium diboride to the composite.

Polymers were the fastest growing materials group in the past 40 years with an average volume increase of $6 \%$ per year compared to steel (2\%) and paper (3\%). In 2007, 260 million tons of polymers were produced worldwide including $\sim 20$ million tons of technical polymers. Especially, the need for high thermal conductive polymers with good insulating properties (e.g. for LED, electro-mobility, ...) will lead to a large increase in demand in the coming years especially for hexagonal boron nitride (BORONID ${ }^{\circledR}$ TC).

The main application for silicon carbide as an additive to the base polymer is to increase the abrasion resistance of the compound. In a pin-on-disc test set-up, with steel as the pin-counterpart, just $20 \%$ of silicon carbide added to a PA66 base polymer decreases the abrasion of the polymer from $35 \%$ to just $4 \%$ if all other parameters are left constant. This is just to show the potential of adding high performance ceramic fillers to polymers. 


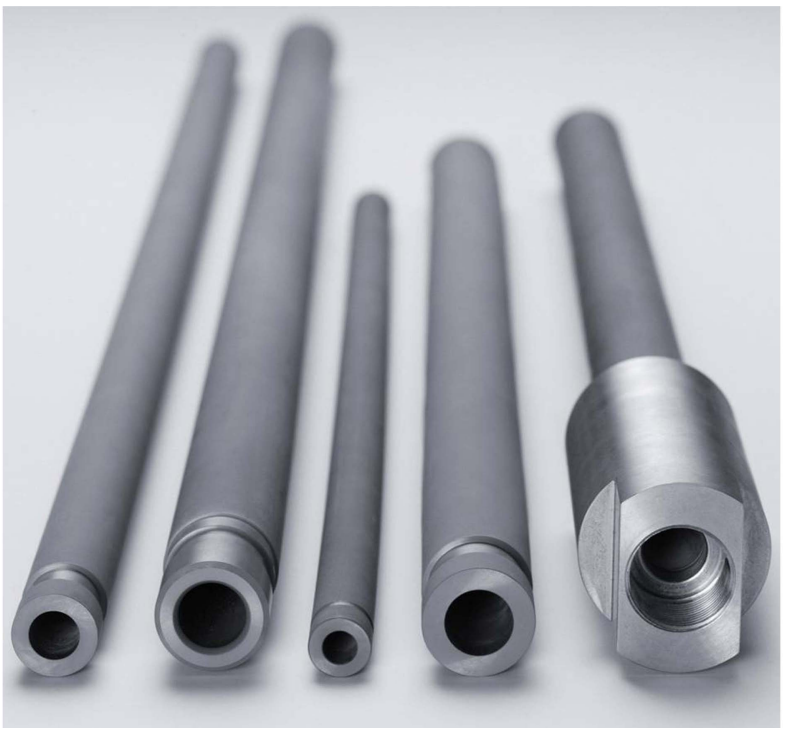

Fig. 6. Thermal couple protection sheaths made of EKatherm ${ }^{\circledR}$ silicon nitride.

\section{Silicon Nitride Properties and Applications}

Property fingerprint

- Chemical resistance to molten aluminum

- High thermal conductivity

- Excellent thermal shock resistance

Liquid-phase sintered silicon nitride (ESK brand name EKatherm $^{\circledR}$ ) finds a series of applications in the aluminum casting industry $\mathrm{as}^{4}$ :

- Heating tubes

- Pump liners

- Riser tubes

- Thermocouple protection sheath

- Components for molten-metal dosing systems

For all of these applications corrosion resistance to molten aluminum as well as very good resistance in contact with slag makes silicon nitride a perfect material. Since preheating is not possible in many of the processes, excellent thermal shock resistance is a necessity for all parts used in the processes. Silicon nitride is known as one of the best thermal shock resistant materials and can also be used as a structural part with certain strength requirements.

When used as a thermocouple protection sheath (Fig. 6) the good thermal conductivity of silicon nitride results in a short response time of the thermocouple. ${ }^{4)}$ Exact and reliable temperature measurement is essential for process control and to achieve high casting quality. Modern lowpressure die-casting processes require a temperature deviation of less than 5 Kelvin.

\section{Silicon Oxide Applications}

Property fingerprint

- For application as a casting crucible for the manufacturing of polycrystalline silicon solar cells, a very low level

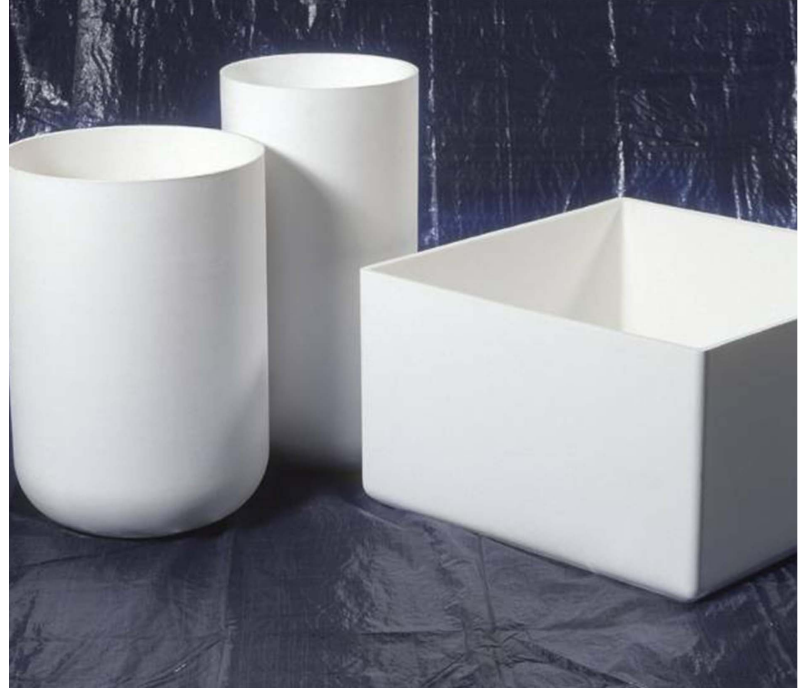

Fig. 7. Fused silica crucibles by Thermo Materials.

of chemical impurities is the main requirement for the base material.

- Thermal shock resistance and reliable performance at temperatures up to $1650^{\circ} \mathrm{C}$ are further requirements for the base material.

Fused silica $\left(\mathrm{SiO}_{2}\right)$ is an excellent thermal insulator with an extremely low coefficient of friction (typical $0.47^{*} 10^{-6} \mathrm{~K}^{-1}$ ). The low thermal expansion results in excellent thermal shock resistance. Thermo Materials, a Ceradyne subsidiary, produces crucibles (see Fig. 7) by slip casting in multiple sizes up to $>1000 \mathrm{~mm}$ for the base length of the rectangular crucible and up to $600 \mathrm{~mm}$ in height. Crucibles can be delivered with a proprietary Silicon Nitride coating, which leads to better deforming. The maximum size is suitable for producing a layer of up to 64 bricks of typical size for solarcell wafer production.

The high purity of the crucibles is due to the very high purity of the raw materials. Minco, another Ceradyne subsidiary, produces high-purity fused silica by its self-developed process. MINSIL ${ }^{\circledR}$ has a purity of $>99.7 \%$ and major impurities like cristobalite and iron are reduced to minimum values.

Fused silica also has the advantage of radiowave, IR and microwave transparency. Combined with the good thermal shock resistance fused silica is the material of choice for missile radomes and could be a suitable solution for other applications with a need for radiation transparent materials.

\section{Summary}

Typical applications of Si-based ceramics have been presented, and the materials properties of silicon carbide, silicon nitride and fused silica have been set in relation to the property fingerprint specified by the customer industries:

EKasic $^{\circledR}$ silicon carbide:

- Microstructure key to tribological performance as sealring or bearing in chemical pumps 
- Integration of an established EKasic ${ }^{\circledR}$ ceramic part into a filter system for the oil and gas industry (PetroCe$\mathrm{ram}^{\circledR}$ ) to provide abrasion and chemical resistance for enhanced oil recovery technologies.

- Gastight EKasic ${ }^{\circledR}$ flow reactors and heat exchangers enable new innovations in the field of chemical processing due to chemical resistance, high thermal conductivity and abrasion resistance

- New customized ceramic fillers increase abrasion/wear resistance for polymer compounds

EKatherm $^{\circledR}$ silicon nitride:

- Multiple applications in non-ferrous metal processing due to the combination of chemical resistance to molten aluminum, thermal shock resistance and good thermal conductivity.

Fused silica (by Minco and Thermo Materials)

- High purity silica powders fabricated to high performance crucibles for production of polycrystalline silicon solar cells.

\section{REFERENCES}

1. J. Eichler and S.M. Schweizer, "Energieeinsparung Durch Verwendung von Gleitringdichtungen aus Siliziumcarbid (SiC)," pp. 186-93 in Dichtungstechnik Jahrbuch 2012, Hüthig Verlag, Heidelberg, 2011.

2. F. Meschke and K. Tuppek, "Vermeidung von Elektrokorrosion an SiC-Gleitringdichtungen in Reinstwasser," pp. 36978 in Dichtungstechnik Jahrbuch 2005, Hüthig Verlag, Heidelberg, 2004.

3. S. Müssig, S. Wagner, A. Kayser, and S. Wildhack, "The Development of Ceramic Screens to Prevent Sand Influx and Erosion in Stimulated Production Wells," Oil Gas Euro. Magazine, [3] 126-30 (2010).

4. K. Uibel, J. Eichler, G. Victor, and C. Lesniak, "Ceramic Materials and Coating Development for Applications in the Non-Ferrous Metals Industry," pp. 323-34, Proceedings of the European Metallurgical Conference 2011, GDMB, 2011.

5. F. Meschke, G. Riebler, V. Hessel, J. Schürer, and T. Baier, "Hermetic Gas-tight Ceramic Microreactors," Chem. Eng. Technol., 28 [4] 465-73 (2005). 